\title{
Sclerotherapy in extrahepatic portal venous obstruction
}

\author{
Y K Chawla, J B Dilawari, G N Ramesh, Upjeet Kaur, S K Mitra, B N S Walia
}

\begin{abstract}
One hundred and twenty two patients who presented with variceal bleeding as a result of extrahepatic portal vein obstruction (EHPO) were entered into the sclerotherapy programme with a mean follow up of 23.69 months (range four to 60 months). Eighteen (14.7\%) patients were lost to follow up, three $(2.4 \%)$ patients underwent surgery, and six (4.9\%) patients died. Variceal obliteration was achieved in the remaining 95 patients requiring $5.4(2.4)$ sessions of sclerotherapy (range 2-18). Seventeen episodes of upper gastrointestinal bleed occurred in 15 patients during sclerotherapy. Recurrence of oesophageal varices was seen in 15 patients. Ten patients developed bulbous gastric varices after obliteration. Major complications including perforation and strictures were seen more commonly in children. Sclerotherapy was associated with a significant reduction in the bleeding rate (bleeds/month/patient) as compared with the presclerotherapy period $(\mathbf{p}<\mathbf{0 . 0 0 1})$. Endoscopic sclerotherapy is an effective and safe modality in the prevention of variceal bleeds in patients with extrahepatic portal vein obstruction.
\end{abstract}

Extrahepatic portal venous obstruction (EHPO) is an important cause of upper gastrointestinal bleeding in our centre, constituting $46 \%$ of all the patients with portal hypertension presenting as a variceal bleed.' In approximately half of the patients, portosystemic shunt surgery is not possible, either because there is a complete block of the splenoportal axis or the diameter of the splenic vein is too small for shunt surgery. Moreover, shunt surgery has its own mortality and morbidity associated with thrombosis of the shunt, postoperative infection, and uncommonly portosystemic encephalopathy..$^{2-7}$ Endoscopic sclerotherapy has become increasingly popular for the treatment of oesophageal varices, both in arresting active bleeding and preventing recurrent bleeding. ${ }^{8-24}$ Most of these studies, however, have been in patients with cirrhosis. This study was planned to assess the effect of sclerotherapy on variceal bleeding/obliteration and patient morbidity/mortality in extra hepatic portal venous obstruction.

\section{Methods}

\section{PATIENTS}

One hundred and twenty two patients (102 men and 20 women), age range from $1 \frac{1 / 2}{2}$ to 55 years (mean age $17 \cdot 2(6 \cdot 4)$ ) with portal hypertension caused by EHPO and recurrent variceal bleeding were entered into the sclerotherapy programme from September 1983 to June 1988 (Table I). No patient had any stigmata of chronic liver disease. All patients had obstruction of the splenoportal venous system as seen on splenoportovenography. Liver function tests were normal in all patients, except three who had a reversed albumin-globulin ratio. Liver biopsy was performed in these three patients to exclude chronic liver disease.

All the patients had bled from oesophageal varices at presentation. Bleeding stopped spontaneously in $92(75.4 \%)$ patients, while it was controlled with the Sengstaken-Blakemore tube in $30(24.6 \%)$ patients before sclerotherapy. The varices were graded from I-IV as described by Paquet $^{13}$ and all the patients treated had grade III-IV varices. Sclerotherapy was performed using a flexible forward viewing endoscope (Olympus GIF-Q) and an indigenously designed needle. ${ }^{25}$

Premedication was given with pentazocine and hyoscine butylbromide (Buscopan) iv to achieve anaglesia and aperistalsis. General anaesthesia was only given to children if they were uncooperative or below six years of age. Oesophageal varices were injected intravariceally (as far as possible) in a circumferential manner near the gastroesophageal junction and $2-3 \mathrm{~cm}$ proximally. The sclerosant used was $3 \%$ sodium tetradecyl sulphate (STD). Usually 1-2 ml sclerosant was injected at each site, not exceeding a total of $10 \mathrm{ml}$ per session. The patients received nil by mouth for four hours after the procedure. Endoscopic sclerotherapy was repeated at three-week intervals until the varices were obliterated and this was considered as the end point of the treatment. Variceal obliteration was achieved when there was non-visualisation

TABLE I Follow up of 122 patients with EHPO *

\begin{tabular}{lcc}
\hline Patients (n) & 122 \\
$\quad$ Male & 102 & \\
Female & 20 & $17 \cdot 2(6 \cdot 4)$ yr $(1 \cdot 5-55 \mathrm{yr})$ \\
Mean age (range) & & 18 \\
Lost to follow up & 104 \\
Available for analysis & 95 \\
Obliteration & 3 \\
Surgery & 6 \\
Died & \\
\hline
\end{tabular}

${ }^{\star}$ Extrahepatic portal venous obstruction.

TABLE II Analysis of 95 obliterated patients

\begin{tabular}{lc}
\hline Sclerotherapy sessions ( $\mathrm{n})$ & 484 \\
Median no/patient & 5 \\
(range) & $(2-18)$ \\
Rebleeds & 15 patients \\
While on sclerotherapy & 5 patients \\
After obliteration & 15 patients \\
Recurrence of varices after obliteration & $8 \cdot 4 \mathrm{mo}$ \\
Average time required for recurrence of varices & $(4-17 \mathrm{mo})$ \\
(range) & 1 patient \\
Mortality after obliteration & \\
\hline
\end{tabular}

Correspondence to: $\mathrm{Dr} J \mathrm{~B}$ and $\mathrm{Head}$, Deciate Profes Hepatology, Postgraduate Institute of Medical, Chandigarh-160 012, India. Accepted for publication 10 May 1989 
of previously present varices at endoscopy or when varices did not bleed after needle puncture - that is, thrombosed varices. Follow up endoscopy was done at six monthly intervals. The results were expressed as mean (SD). Statistical analysis was done using Student's $t$ paired tests with significance accepted at the $5 \%$ level.

\section{Results}

At the time of analysis, follow up ranged from four to 60 months (mean 29.00 (15.09)). Of these patients, 18 were lost to follow up after one to six sessions of sclerotherapy, leaving 104 patients available for analysis. Three patients underwent surgery and six died (Table I).

\section{OBLITERATION}

Variceal obliteration was achieved in 95 of the 104 patients $(91 \cdot 3 \%)$, requiring a total of 484 sessions (median 5, range 2-18).

\section{REBLEEDS WHILE ON SCLEROTHERAPY (Table II)}

Seventeen rebleeding episodes occurred in 15 (15.8\%) of the 95 patients who achieved obliteration. Endoscopy was performed during 14 such episodes. In seven episodes the rebleeding was from an oesophageal ulcer and was controlled with antacids and antireflux measures. In three, actively bleeding oesophageal varices were found and emergency sclerotherapy carried out. In the remaining four bleeding episodes, the source was difficult to determine and each of these episodes was managed conservatively and the patient continued on the sclerotherapy programme. Three other rebleeds (all of which were minor) manifested as haematemesis and melaena, occurred at home and stopped spontaneously.

REBLEED AFTER OBLITERATION (Table II) Five of the 95 patients who had achieved obliteration had a recurrence of upper gastrointestinal bleed. Endoscopy at the time of bleed showed that two of the patients bled from gastric varices (two of 10 patients with bulbous gastric varices), one bled from an oesophageal varix (grade III), and two others from gastric erosions after taking analgesics.

\section{RECURRENCE OF VARICES AFTER OBLITERATION (Table II)}

The 95 patients in whom varices were obliterated were followed up for a mean period of 23.69

TABLE III Bleeding rates before, during, and after sclerotherapy in patients with EHPO

\begin{tabular}{|c|c|c|c|c|}
\hline & Period & $\begin{array}{l}\text { Total } \\
\text { bleeds }\end{array}$ & $\begin{array}{l}\text { Patient } \\
\text { (mo })\end{array}$ & $\begin{array}{l}\text { Bleeds/month/ } \\
\text { patient } \\
\text { (mean (SEM) }\end{array}$ \\
\hline $\begin{array}{l}\text { (i) } \\
\text { (ii) } \\
\text { (iii) } \\
\text { (iv) }\end{array}$ & $\begin{array}{l}\text { Before sclerotherapy } \\
\text { During sclerotherapy } \\
\text { Post obliteration } \\
\text { Total period (ii+iii) }\end{array}$ & $\begin{array}{r}248 \\
14 \\
5 \\
19\end{array}$ & $\begin{array}{r}5294 \\
465 \\
2014 \\
2479\end{array}$ & $\begin{array}{l}0.208(0.034) \\
0.028(0.008) \\
0.0015(0.012) \\
0.008(0.001)\end{array}$ \\
\hline
\end{tabular}

p value Student's $t$ test: (i) $v$ (ii) $\mathrm{p}<0.001$; (ii) $v$ (iii) $\mathrm{p}<0.001$; (i) $v$ (iv) $\mathrm{p}<0.001$.
(15.06) months (range 2-53). Recurrence of oesophageal varices was encountered in 15 patients $(15 \cdot 8 \%)$ after a mean interval of $8 \cdot 4$ months (range four to 17 months). Ten patients had grade II varices, and five had grade III varices. One patient developed a doudenal varix, while 10 other patients developed bulbous gastric varices in the fundus.

\section{EFFECT OF SCLEROTHERAPY ON THE BLEEDING RATE (Table III)}

The number of bleeds and the number of patient months at risk of bleeding were calculated for (i) Presclerotherapy period - that is, from the time of first bleed to the date of first sclerotherapy. (ii) During sclerotherapy - that is, from the date of first sclerotherapy to the date on which the varices were declared 'obliterated'. (iii) Postsclerotherapy period - that is, from the date of obliteration to the date of last follow up. (iv) Total period - that is, during sclerotherapy+ post sclerotherapy periods.

Ninety five patients had a total of 248 bleeds over 5294 months at risk before the start of sclerotherapy (a mean risk of 0.208 bleeds/ month/patient). During sclerotherapy, 14 bleeds occurred over 465 months (a mean risk of 0.028 bleeds/month/patient). After obliteration, over a total follow up period of 2014 months, only five bleeds occurred in the 95 patients (a mean rate of 0.0015 bleeds/month/patient). Compared with the presclerotherapy period, the Student's $t$ paired test revealed a statistically significant reduction of bleeds during sclerotherapy $(p<0.001)$, in the post sclerotherapy period $(p<0.001)$ and also when the total period of treatment was considered $(\mathrm{p}<0.001)$.

\section{COMPLICATIONS (Table IV)}

Oesophageal ulcers were seen in 24 patients $(25 \cdot 3 \%)$, seven of whom bled from them. All ulcers healed after treatment with antacids and antireflux measures. Strictures causing dysphagia were encountered in four patients and these resolved with antacids and antireflux measures within two months.

Perforation occurred in three of 26 patients less than 12 years of age and was detected within seven days of sclerotherapy when they complained of fever and severe pain on swallowing liquids. A gastro-conray study, in each case, showed evidence of perforation. One perforated when he was given more than $4 \mathrm{ml}$ of $3 \%$ sodium tetradecyl sulphate at one site. The second patient was very restless during the procedure and the sclerosant might have penetrated the

TABLE IV Results according to age in 95 obliterated patients

\begin{tabular}{lrcr}
\hline & $>15 y r$ & $<15 y r$ & Total \\
\hline Patients obliterated (n) & 58 & 37 & 95 \\
$\quad$ Surgery & 2 & 1 & 3 \\
Death & 3 & 3 & 6 \\
Complications & & 8 & \\
$\quad$ Ulcer & 16 & 1 & 24 \\
Pain & 3 & 2 & 4 \\
Fever & 2 & 3 & 3 \\
Perforation & 0 & 3 & 4 \\
Stricture & 1 & & \\
\hline
\end{tabular}


oesophageal wall. The third patient perforated after his gastric varices close to the gastrooesophageal junction were injected. Two of these three patients required a feeding jejunostomy, while one improved with conservative treatment alone. All the patients are alive and well.

Fever lasting for 48 hours was encountered in four patients but resolved spontaneously without treatment and without bacteraemia.

Severe retrosternal pain lasting for more than six hours occurred in four patients and tended to recur after each session of sclerotherapy.

SURGERY (Table IV)

Three patients had successful surgery (two a side-to-side lienorenal shunt, and one an oesophagogastric devascularisation). Surgery was chosen because these patients could not afford to travel long distances each time to receive sclerotherapy.

MORTALITY (Table IV)

Six $(5 \cdot 77 \%)$ patients died of bleeding - five before having been obliterated, and one 12 months after obliteration, probably from a bleeding gastric varix. All died at home for want of timely medical attention and of the five who died before variceal obliteration, three died after six sessions, one after three sessions, and one after two sessions of sclerotherapy.

RESULTS ACCORDING TO AGE (Table IV)

The patients were arbitrarily divided into 'adults' when they were above 15 years and 'children' when below 15 . No significant difference complications such as chest pain, fever, and oesophageal ulceration was observed between the two groups. Perforation and stricture, however, were more common in children than adults.

\section{Discussion}

Extrahepatic portal obstruction is a major cause of bleeding varices in India. 'The natural history and prognosis of this disease are variable and unpredictable $^{26}$ and hence the disagreement regarding the optimal therapy.

Until recently, a conservative approach to management comprising basic resuscitation measures and blood transfusion had been advocated in the belief that shunt surgery was associated with a high complication and failure rate. Moreover liver function is not compromised in EHPO. A major factor that weighs against the adoption of conservative management is the incidence of post-transfusion hepatitis (approximately 10\%) in addition to the financial burden and psychological stress of repeated admissions to the hospital..$^{27-29}$

It is therefore important that in order to reduce the morbidity and mortality associated with frequent variceal bleeds and repeated blood transfusions management of this condition must be aimed at prevention of recurrent variceal haemorrhage. This could either be achieved by decompressing the portal venous system by surgical shunts, or through obliteration of the submucosal oesophageal varices by sclerotherapy.

The results of surgical decompression need to be evaluated with respect to the operative mortality, rebleeding rate and encephalpathy ${ }^{2-7}$ and compared with the results of sclerotherapy. Two large series available from India ${ }^{23}$ one of them from our own centre, ${ }^{3}$ deal with the results of shunt surgery in extrahepatic portal venous obstruction. The operative mortality in these two series was $2 \cdot 2 \%$ and $10 \cdot 1 \%$ respectively. ${ }^{23}$ The rebleeding rates (which would logically approximate the incidence of blocked shunts) were $15 \%$ and $21.4 \%$ respectively and encephalopathy consequent to portal diversion occurred in none of the patients in the two series. These results would seem to indicate that surgery has a definite role to play in the management of patients with EHPO. A cumulative analysis of shunt surgery in EHPO, however (which also included one of the above mentioned series from India) quoted the overall mortality and rebleeding rate to be $4 \cdot 7 \%$ and $45 \cdot 3 \%$ respectively. ${ }^{+}$

An alternative therapy - that is, sclerotherapy - has been subjected to much critical analysis in patients with portal hypertension caused by cirrhosis. ${ }^{8-11}$ A number of studies are available evaluating the effect of sclerotherapy in patients with $\mathrm{EHPO}^{12-24}$ but in most of these the numbers of patients were small (range 4-16 patients) and a large proportion had already undergone earlier surgery for portal hypertension. Moreover, the complications and follow up of patients with EHPO have not been dealt with separately. In two of the larger series available to date that included 39 and 36 patients with EHPO, variceal obliteration rates of $84.6 \%$ and $92 \%$ were achieved. ${ }^{23}$ Our study of 104 patients is, to our knowledge, the largest series of patients with EHPO undergoing sclerotherapy. The obliteration rate of $91 \cdot 3 \%$ compares well with the figures available. Our analysis of the efficacy of sclerotherapy was based on the bleeding rate per month, before, during, and after sclerotherapy. A significant fall in the bleeding rate per month $(p<0.001)$ after the start of sclerotherapy following a bleed, is sufficient evidence that sclerotherapy has a major role to play in the management of this condition. Complications, major and minor, occurred in approximately one third of patients. This figure is comparable with reports of complications in other studies. ${ }^{23}$

Oesophageal ulceration was a major complication in our series. It was seen in $25.3 \%$ of patients in contrast with $59 \%$ reported by Kahn. ${ }^{23}$ This difference in the incidence of ulceration may have resulted from sclerotherapy being performed at weekly rather than three weekly intervals as in our study. There is reason to believe therefore that ulcers may in fact be an effect of sclerotherapy rather than a complication and more frequent sessions may discover more ulcers.

Oesophageal strictures were seen more commonly in children below 15 years of age and all of these resolved with conservative management without oesophageal dilatation. One can only postulate that the healing of an ulcer at the site of stricture formation with simultaneous relief of 
oesophageal wall oedema and spasm might contribute to the disappearance of the stricture. This could explain the transient dysphagia that can occur after sclerotherapy. ${ }^{30-32}$

More serious complications such as perforation were fortunately rare and only occurred in children. This complication has been reported using rigid endoscopes ${ }^{33}{ }^{34}$ and rarely with fibreoptic endoscopes. ${ }^{23}$ We feel that a careful technique, adequate sedation, and the use of small volumes of diluted sclerosant may avoid these complications.

Endoscopic sclerotherapy is therefore, an effective and safe therapy for patients with extrahepatic portal venous obstruction. A comparison with the results of surgery in the two large series available from India studying similar groups of patients show that the bleeding rate after variceal obliteration is actually less than the rebleeding rate after shunt surgery. ${ }^{23}$ Moreover, a large proportion (54\%) of patients with EHPO either have a complete splenoportal block or a splenic vein that is small in diameter and hence non-shuntable (unpublished observations). Finally, the longterm effects of portal diversion in such patients are not yet known. There are reports to suggest that operated patients with EHPO may develop encephalopathy despite good liver function. ${ }^{26}{ }^{35}$ These advantages, in addition to the fact that the complication rates observed are not very different from the surgical series, make endoscopic sclerotherapy the procedure of choice in such patients. We do, however, acknowledge that sclerotherapy has a disadvantage in terms of time and frequent trips to the hospital in order to complete the course of treatment.

In conclusion, it is felt that endoscopic sclerosis of oesophageal varices is an effective treatment for patients with EHPO, achieving results comparable with those of shunt surgery, with the advantage it can be done in the outpatient department. The final opinion, however, can only be given after sclerotherapy and shunt surgery are compared in a prospective randomised trial with a longterm follow up. One such trial has been undertaken in our centre and the results of which will be available in the near future.

1 Dilawari JB, Kaur U, Narayanan VA, et al. Pattern of uppe gastrointestinal hemorrhage in Northern India - an endoscopic study of 316 patients. $\mathcal{F}$ Gastroenterol Hepatol 1987; 2 . 443-9.

2 Pande GK, Reddy VM, Kar P, et al. Operations for porta hypertension due to extrahepatic obstruction. Results and 10 years follow up. Br Med F 1987; 29: 1115-7.

3 Mitra SK, Kumar V, Datta DV, et al. Extrahepatic portal obstruction. A review of 70 cases. $\mathcal{F}$ Pediatr Surg 1978; 13 . 51-4.

4 Fonkalsrud EW. Surgical management of portal hypertension in childhood. Arch Surg 1980; 115: 1043-5.

5 Voorhees AB, Price JB. Extrahepatic portal hypertension: A retrospective analysis of 127 cases and associated clinical retrospective analysis of 127 cases and ass
implications. Arch Surg 1974; 108: 338-41.

6 Clatworthy HW Jr, Fonkalsrud EW, Myers NA, Robinson
MJ. Management of extrahepatic portal hypertension in children. Ann Surg 1974; 180: 487-93.

7 Bismuth H, Franco D, Alagille D. Portal diversion for portal hypertension in children. The first ninety patients. Ann Surg 1980; 192: 18-24.

8 Macdougall BRD, Westaby D, Theodossi A, Dawson JL, Williams $R$. Increased long term survival in varicea haemorrhage using injection sclerotherapy. Results of a haemorrhage using injection sclerother

9 The Copenhagen Esophageal Varices Sclerotherapy Project. Sclerotherapy after first variceal haemorrhage in cirrhosis: a Sclerotherapy after first variceal haemorrhage in cirrhosis: a
randomised multicentre trial. $N$ Engl $\mathcal{F}$ Med 1984; 311: randomised

10 Sauerbach T, Weinzierl M, Kopcke W, Paumgartner G. Long term sclerotherapy of bleeding esophageal varices in patients with liver cirrhosis. Scand $\mathcal{F}$ Gastroenterol 1985; 20: 51-8.

11 Paquet KJ. Prophylactic endoscopic sclerosing treatment of the esophageal wall in varices. A prospective controlled randomised trial. Endoscopy 1982;14:4-5.

12 Stellen GP, Lilly JR. Esophageal endosclerosis in children. Surgery 1985; 98: 970-5.

13 Paquet KJ. Ten years' experience with paravariceal injection sclerotherapy of esophageal varices in children. $\mathcal{f}$ Pediatr Surg 1985; 30: 109-12.

14 Vane DW, Boles ET, Clatworthy HW. Esophageal sclerotherapy: an effective modality in children. $\mathcal{F}$ Pediatr Surg 1985; 20: 703-7.

15 Spence RAJ, Johnston GW, Odling-Smee GW, Rodgers HW. Bleeding oesophageal varices with long term follow-up. Arch Dis Child 1984; 59: 336-40.

16 Stamatakis JD, Howard ER, Psacharopoulous HT, Mowat AP. Injection sclerotherapy for oesophageal varices in children. Br f Surg 1982; 69: 74-5.

17 Lilly JR, Van Stiegmann G, Stellin G. Esophageal endosclerosis in children with portal vein thrombosis. F Pediatr Surg 1982; 17: 571-5.

18 Atkinson JB, Woolley MM. Treatment of oesophageal varices by sclerotherapy in children. Am F Surg 1983; 146: 103-6.

19 Dall'Oglio L, Bagolan P, Ferro F. Ponticell A, Cadranel S, Rivoscecchi M. Endoscopic injection sclerosis of Rivoscecchi M. Endoscopic injection sclerosis of
oesophageal varices in children - indications and techniques. Endoscopy 1984; 16: 98-100.

20 Van Stiegmann G, Stellin G, Karrer FM, Lilly JR. Endoscopic sclerosis of oesophageal varices in children [Abstract]. Gastrointest Endosc 1985; 31: 137

21 Donovan TJ, Ward M. Shepherd RW. Evaluation of endoscopic sclerotherapy of esophageal varices in children. $\mathcal{F}$ Paediatr Gastroenterol Nutr 1986; 6: 696-700

22 Thatcher BS, Sivak MV, Petrini JL. Endoscopic sclerotherapy for bleeding oesophageal varices secondary to extrahepatic portal vein obstruction. Gastroentest Endosc 1987; 33: 214-9.

$23 \mathrm{Kahn}$ D, Terblanche J, Kitano S, Bornman P. Injection sclerotherapy in adult patients with extrahepatic porta venous obstruction. Brf Surg 1987; 74: 600-2.

24 Howard ER, Stringer MD, Mowat AP. Assessment on injection sclerotherapy in the management of 152 children injection sclerotherapy in the management of 152 chilc
with oesophageal varices. $B r \mathcal{F}$ Surg $1988 ; 75 ; 404-8$.

25 Dilawari JB, Chawla Y, Locham HS, et al. A low cost endoscopic sclerotherapy needle. Trop Gastroenterol 1985; 6: 104-6.

26 Webb LJ, Sherlock S. The aetiology, presentation and natural history of extrahepatic portal venous obstruction. $Q \mathcal{F} \mathrm{Med}$ 1979; 192: 627-39.

27 Clatworthy HW, Nahmad M, Hollabaugh RS. Presinusoida extrahepatic portal hypertension. A review of thirty-five cases variously treated. F Pediatr Surg 1978; 11: 125.

28 Alvarez F, Bernard O, Brunelle F, et al. Portal obstruction in children. I. Clinical investigation and haemorrhage risk. $\mathcal{J}$ Pediatr 1983; 103: 696-702.

29 O'Donell TF, Gembarowicz RM, Callow AD, et al. The economic impact of acute variceal bleeding. Cost effectiveness, implications for medical and surgical therapy. Surgery 1980; 88: 693-701.

30 Agha AP. The esophagus after endoscopic injection sclerotherapy: Acute and chronic changes. Radiology 1984; 153 . 37-42.

31 Tihansky DP, Reilly JJ, Schade RR, et al. The esophagus after injection sclerotherapy of varices. Immediate post operative changes. Radiology 1984; 153: 43-7.

32 Sauerbach $\mathrm{T}$, Wirsching $\mathrm{R}$, Leisner $\mathrm{B}$, et al. Esophageal function after sclerotherapy of bleeding varices. Scand $\mathcal{f}$ Gastroenterol 1983; 17: 745-51.

33 Paquet KJ, Oberhammer E. Sclerotherapy of bleeding esophageal varices by mean of endoscopy. Endoscopy 1978 10: 7-12.

34 Barsoum MS, Mooro HAW, Bolous FI, et al. The complications of injection sclerotherapy of bleeding esophageal varices. Br f Surg 1982; 69: 79-81.

35 Voorhees AB Jr, Chaitman E, Schneider S, et al. Portalsystemic encephalopathy in the non-cirrhotic patient: effect of portal-systemic shunting. Arch Surg 1973; 107: 659-63. 